\title{
Identifying Likeable Attributes: \\ A Qualitative Study of Television Advertisements in Asia
}

\author{
Kim-Shyan Fam \\ Department of Marketing \\ School of Business \\ University of Otago \\ P O Box 56 \\ Dunedin, New Zealand \\ Tel: + 6434797692 \\ Fax: + 6434798172 \\ Email: kimfam@business.otago.ac.nz \\ and \\ David S. Waller \\ School of Marketing \\ University of Technology, Sydney \\ PO Box 123, \\ Broadway, NSW 2007, \\ Australia \\ Tel: + 61295143976 \\ Fax: + 61295143535 \\ Email: david.waller@uts.edu.au
}

The authors would like to thank NFO WorldGroup - Hong Kong for undertaking the research and Lowe Advertising (HK) Limited for granting me access to the dataset. 


\title{
Identifying Likeable Attributes: A Qualitative Study of Television Advertisements in Asia
}

\begin{abstract}
This paper reports the findings of a cross-cultural qualitative research undertaken across five Asian cities (Hong Kong, Shanghai, Jakarta, Bangkok and Mumbai) to discuss Asian consumers' attitudes towards television commercials in their respective country/city. The study was conducted in using focus groups with the aim to provide an insight into the construct of “advertising likeability”. In an effort to explore this, a process was undertaken to be able to compare the cross-cultural samples and discover some cultural differences.
\end{abstract}

Keywords: Advertising Likeability, Television Advertising, Asia, Cross-Cultural, Focus Groups

\section{Introduction}

The study of culture and its influence has been commonly sighted in cross-cultural research. In the advertising literature the influence of culture has been observed in a number of different areas, including advertisers' choice of promotional tools (Fam and Merrilees, 1996, 1997); advertising restrictions (Deng, Jivan and Hassan, 1994; Firth 1996; Waller and Fam, 2000); advertising strategy and execution (Cheng, 1994; Lin and Salwen, 1995); advertising appeal (Mueller, 1992; Pollay and Galangher, 1990), and on brand image strategies (Roth, 1995). Cultural values reflected in advertising content have also been widely investigated, and when conveyed through advertising messages, cultural values can be regarded as powerful forces shaping consumers' motivations, lifestyles and product choices (Tse et al., 1989). The cultural values reflected in advertising content in such countries as Hong Kong (Chan, 1999); China (Cheng, 1994); India (Srikandath, 1991), Japan (Belk et al., 1985; Belk and Pollay, 1985; Belk and Bryce, 1986; Lin, 1993; Mueller, 1987; 1992), and the United Kingdom (Frith and Sengupta, 1991; Frith and Wesson, 1991; Katz and Lee, 1992) have been investigated and compared with advertising from the United States. 
However, it should be noted that most of these studies used quantitative research techniques, such as surveys, experiments or content analysis. A qualitative technique such as focus groups, while popular with the advertising industry, is rarely used by advertising academics in crosscultural studies. This is despite the obvious advantages of focus groups including that it allows for the collection of more detailed in-depth responses and provides information that would otherwise be difficult or impossible to obtain through more structured methods of interviewing (Stewart \& Shamdasani 1990). The unstructured interviewing format allows researchers to be flexible with regards to changing questions asked and aspects of the study design in response to information. The spontaneity and stimulation of the group situation motivates a large number of creative responses and is thus useful in generating new ideas. Also focus groups allow sensitive concepts to be exposed to a limited and pre-selected group of respondents in a tightly controlled environment (Morgan 1997).

According to Davies (2004), focus groups are a particularly useful method of data collection in Asia due to the strong oral tradition where the exchange of information by word of mouth is central to Asian cultures and the way business is done. Another advantage of using the focus groups is that Asian people value their flexibility, and hence putting something down on paper often signals a commitment that can be referred to later. To Asians, life changes quickly that it is a commitment that many don't want to make. Furthermore, the Asian countries are a myriad of societies with different cultural values and linguistic capabilities. Using focus groups would reduce the difficulties of translating the questionnaires that often results in the changes in the 'meaning' of questions (Davies, 2004). 
Of course the disadvantage of focus groups includes that a focus groups contain only a small number of respondents, and so it is not possible to make generalisations on the population as a whole, the problem of gathering a fairly representative group, finding a sufficiently experienced moderator, problems if certain group members dominate discussion, and the discussion usually only covers the specific needs of the client thereby ignoring external factors that may ultimately have an effect and uncertainty on how to analyse the discussion. Still, from an academic point of view, it would be hoped that more qualitative research could be utilised for cross-cultural advertising research.

In this study, cross-cultural qualitative research was undertaken across five Asian cities (Hong Kong, Shanghai, Jakarta, Bangkok and Mumbai) to discuss Asian consumers' attitudes towards television commercials in their respective country/city. The study was conducted in using focus groups. The findings, although not representative of the various Asian cultures, provide some information about aspects of the different cultures.

\section{Consumer Attitudes Towards Advertising}

As consumers continue to be exposed to an ever-increasing barrage of diverse advertising message via various media, it is little wonder advertisers are having a difficult time getting advertisements to be heard. Advertising and its associated creativity relies upon the audience for success (Cummins, 1996). Nevertheless it is important to remember advertising is more often than not deemed to be an unwelcome intrusion, regarded by many consumers as a constant source of irritation. Hence, many consumers often make a conscious effort to avoid advertising communications. In fact both academics and practitioners content it has become second nature 
for consumers to 'zap' or 'flick' television channels. In recent years, much literature postulates that young audiences are sophisticated, cynical yet inconsistent in their use of mass media. It has been claimed that most young adults in the 1990s prefer visual imagery to the written word (Postman 1986; Reeves \& Nass 1996). As Postman (1986, p74) commented "seeing, not reading, became the basis for believing" since television, billboards, and posters focus on the image as the main form of information.

Cummins (1996) claims people watch television to gain access to information and entertainment, thereby utilising an opportunity to escape reality rather than using the medium to watch, ingest and analyse advertising messages. In the instance(s) where attention is awarded, consumers (generally speaking) do not concern themselves with thinking too deeply about advertising. A typical consumer will not attempt to decipher and comprehend intricate, complex advertising messages; they simply 'switch off'. Stewart and Ward (1994) recommended that media research pursue 'a better understanding of how and when people use and interact with various media', not a better understanding of the medium itself (p.355). "Research should address what consumers do with advertising instead of what advertising do to consumers" said Bauer (1964) and echoed by more recent studies like Hirschman and Thompson (1997) and O’Donohoe (1994). This viewpoint is exemplified by Greene (1992) who contends that only one third of commercials a person is exposed to will make any active impression on memory. "Of those attended to, only half are correctly comprehended and fewer than 5\% is actively recalled for as long as 24 hours". Thus attention and the opportunity to motivate (through influence) are often lost amongst the clutter of modern-day advertising. 
There is a belief, however, that the generic concept of television advertising can also be offputting to the average consumer, and as a result they are inclined to 'switch-off' before the first advertisement even appears. Biel and Bridgwater (1990) contends that the concept of advertising is disliked more than individual advertisements. Collett (1994), based on the observation of people's television viewing habits, indicated that while overall attention to television commercials seemed to be quite low, people tended to watch either all of the advertisements or none. Thus what Collett (1994) is alluding to is that likeability has an important role to play in facilitating consumer responsiveness towards advertising, thereby creating the opportunity to develop an effective communication. However, it cannot be assumed that likeability provides the single best measure or indicator of advertising effectiveness. In other words, it would not be accurate to draw conclusions based upon advertising likeability as a variable in isolation.

\section{Advertising Likeability}

The inference that advertisements that are liked by consumers will be given greater mental processing effort is logical. However, the desired outcome may only be achieved if the advertisements are viewed in ideal circumstance (i.e. full attention is bestowed upon the advertisement as environmental variables remain constant). The implication being that advertising likeability provides the potential to facilitate consumer responsiveness, if most impacting factors are held constant. A further point is that liking might indeed engenders trust through the implementation of source credibility. However, the accomplishment of consumer trust would also be reliant upon other elements such as maintaining high product quality. Additionally if the advertisement is disliked then credibility may be lost as negative connotations develop. 
MacKenzie and Lutz (1989) carried out a laboratory test to ascertain the relative influence of Aad (Attitude towards the ad) on Ab (Attitude towards the brand), and concluded that Aad had a considerable and direct influence on $\mathrm{Ab}$ and at the same time it exert far less influence over cognitive brand associations. Further, they conclude that persuasion is more likely to result from advertising executive variables than from specific information on the product or brand. The Advertising Research Foundation (ARF) undertook a copy research validity project and identified and emphasised the role of 'liking' a commercial as an important evaluative measurement (Harley and Baldinger, 1991). A fundamental question raised by the research was exactly what drives commercial liking? Is it entertainment value, or is it content, or the communication element of the advertising message? These underlying factors were found to relate to information, liking, persuasion, and brand name recall. Doubtless the importance of each varies, both with the objectives of the commercial, and with the type and status of the brand to be advertised. However, all are potentially important components of advertising and all should be covered in any complete copy-testing method.

Biel and Bridgwater (1990) suggested likeability does have a persuasive effect, as it can directly affect feelings towards a brand. "When we like the advertising, we are more inclined to like the brand as well. It is just a form of traditional emotional conditioning”. Likeability was found to be a complex concept, intertwined with various factors, and Biel and Bridgwater identified five dimensions which they labeled 'ingenuity', 'meaningfulness', 'energy', 'warmth', and 'rubs the wrong way.' They concluded that the overall contribution each of these basic factors makes towards explaining advertising likeability differs from one product category to another. 
Consequently no concise and accurate conclusions can be drawn. Aaker and Stayman (1990) also carried out a similar study covering 80 commercials and a sample of 300 respondents per commercial. When responses were reduced to five basic factors, the two studies came up with virtually identical findings. Fam (2006) conducted a five-country study of what constitutes ad likeability and identified seven attributes, namely 'entertaining', 'warmth', 'relevant to me', 'soft sell', 'strong/distinctive/sexy', 'status appeal', and 'trendy/modernity/stylish'. Although the first three attributes (entertaining, warmth, relevant to me) are similar to Biel and Bridgwater’s (1990) likeable dimensions, the remaining four attributes (soft sell, strong/distinctive/sexy, status appeal, trendy/modernity/stylish) can be described as uniquely Asian.

There have been a number of studies which have looked advertising likeability and its role in the advertising process relating such things as brand recall, brand attitude and brand preference (Walker, 1990; Thorsen 1991; Franzen, 1994; Walker and Dubitsky 1994; Hollis 1995). While these studies relating to the differing viewpoints of advertising likeability highlights an inherent need for further in-depth research, undoubtedly the likeability variable has the potential to significantly impact the effectiveness of advertising communications. Although prior studies have succeeded in establishing the various dimensions of ad likeability and indicated the presence of a relationship between advertising likeability and consequent effectiveness, very few of these studies looked beyond the national boundary let alone undertake an inter-country comparison. Most of the existing studies focused on American advertisements in America. As such, an opportunity arises to examine whether there are differences in ad likeability across selected Asian markets with distinct culture and religious background. 
Specifically, this study will examine television advertising messages from Hong Kong, Shanghai, Jakarta, Bangkok and Mumbai. Note that, where relevant, the city status of these five cities (Hong Kong, Shanghai, Jakarta, Bangkok and Mumbai) will be used interchangeably with countries respectively. In addition, although Hong Kong is part of China, its distinct status as a world city, long history of Western influence, culture, heritage and economic development warrants a city state treatment. Consequently, we will refer to Hong Kong as a 'country' for the purpose of this study. Further, this study will discuss the results of focus groups conducted in these cities, while previous studies have concentrated more on surveys, experiments and content analysis.

Focus groups interviews are increasingly being used in market research to provide marketers with consumer information on advertising campaigns and product launches, in gauging consumers' attitudes and behaviour and in developing marketing strategies (Reed and Payton, 1997; Crabtree and Miller, 1992; Hedges, 1985; Keown, 1983). Wright (1996) claims that focus group interviews are a more effective method in extracting sensitive information from industry experts. Unlike earlier similar studies, the present study is intended to extract in-depth information from the respondents on their attitudes towards certain advertisements. Morgan (1997) argues that "focus groups interviews are characterized by the explicit use of the group interaction to produce data and insights that would be less accessible without the interaction found in a group". Reed and Payton (1997) claims that the statements made in a group may be less constrained than those made in individual interviews.

\section{Methodology}




\section{Country/City Selection}

Five cosmopolitan cities (Hong Kong, Shanghai, Jakarta, Bangkok and Mumbai) were selected representing four countries (i.e., China, Indonesia, Thailand and India) for this comparative study of ad likeability for several reasons:

(1) the five countries represent diverse work-related cultural values (Hofstede 1980). For instance, India is more individualists compared to Hong Kong, Thailand or Indonesia, while Indonesians strongly believed there is inequality in status than the citizens of the other four countries. Thais feel more threatened by uncertainty and ambiguity, while Hong Kong are more masculine and long term oriented than their counterparts in the other countries;

(2) the citizens of the five countries adhered to different religion, for example, India is a Hindu society, Indonesia is Muslim, China is an atheist society with no officially sanctioned religion, Thailand is a Buddhist nation, and Hong Kong is a city with a good mixture of religions with Taoism enjoying a larger number of followers;

(3) the five countries have a 'homogeneous' set of populations which makes this study less susceptible to argument against neutrality of advertisement contents, a common practice in multi-racial societies. That is, the predominant race in China it is Han Chinese, Cantonese in Hong Kong, Indonesian Malay in Indonesia, Thai in Thailand and Indian in India.

(4) there are wide variations of ad spending in real local currency among the five countries. For instance, China dominated the industry, excluding classified advertising, in 1999 with a total spending of US $\$ 4,158 \mathrm{~m}$ followed by Hong Kong (US\$3,049m), India (US\$1,788m), Thailand (US\$1,100m) and Indonesia (US\$714m). Television was the largest advertising medium in 1998 and 1999 in these five countries (World Advertising Trends, 2001).

(5) the five countries are in different stages of economic development. Asiaweek (2001) magazine reported Hong Kong's nominal per capita GNP in 2001 was at US\$24,303, representing the highest amongst the five countries, followed by Thailand (US $\$ 1,984$ ), China (US\$840), Indonesia (US\$692) and India (US\$459). Obviously the larger cities like Shanghai, Jakarta, Bangkok and Mumbai have higher per capita income than the rest of the respective country.

A point worth noting is that with the inclusion of China, India and Indonesia, three of the world's largest population countries in this study, the findings, although not representative of the various Asian cultures, will be of significant value to international advertisers seeking a market share in these countries where over $60 \%$ of the world populations live.

\section{Data Collection}


The data was gathered from two focus group interviews ( 1 male and 1 female) conducted in each city. All respondents were aged between 25 and 30 years old and frequent TV viewers (spending 5 hours or more watching TV in an average week). Each group comprised of 8 people and the interview lasted between 40 and 60 minutes. In each focus group several of the most liked locally produced television commercials were presented to the participants and the discussion that followed centered around visual images that they most liked. As the data was informant driven rather than researcher driven, this methodology affords an opportunity to have the respondents more freely express and expand on their thoughts and feelings about the topic under investigation.

\section{Results}

After viewing the commercials, the participants were asked to describe what they liked about the advertisements. Overall, the respondents from the two focus groups in each of the five cities were unanimous in pointing out the reasons for liking the advertisements. Funny, amusing / humorous, and interesting were the commonly sighted reasons for liking the advertisements. Adjectives relating to the 'Warmth' attribute have also been sighted in Shanghai, Jakarta, Bangkok and Mumbai. The qualitative findings indicate that the foundation for liking a television commercial is 'entertainment'. In other words, for a television commercial to be liked it must consist at least an 'entertaining' adjective. Once this adjective was 'built into' the commercial, other adjectives can integrated into the commercial. Variation in the use of other adjectives will, nevertheless, depend on a number of factors like cultural values, country of origin and market-related factors to name a few. 
With the aim of constructing a composite picture of the top 5 most liked television commercials in each of the five cities based on the reasons generated by the qualitative focus group interviews, and discussion with local industry representatives, five descriptions of likeable television commercials for each city were established.

Hong Kong: Fun/Escapism - Hong Kong people seek immediate sensational stimulation from the advertisements. Being amusing / humorous / funny, entertaining, interesting and having a celebrity are commonly cited reasons for liking. They are also attracted by unique / creative storylines that contain unexpected elements, lovely characters, and happy and comfortable settings.

Shanghai: Warmth/Team Spirit - Shanghainese are attracted to the happy and warm feeling generated by family or childhood (babies) and the beautiful and refreshing scenery. Having a creative / unique storyline, a funny / amusing / humorous theme and nice music are also seen as key drivers. Cooperativeness, togetherness, pride and team membership are further drivers of likeability.

Jakarta: Charming/Aspiring - Being funny / amusing / humorous, entertaining and having an interesting theme or setting are important. Also, a loving / touching / warm storyline, beautiful and natural scenery all contribute to likeability. Other drivers include simplicity, a desire to own, to emulate or be associated with a celebrity, and dream a giant dream storyline.

Bangkok: Slice of Life - Besides creativity and having a funny / amusing / humorous storyline, showing beautiful (Thailand) scenery, communicating a true to earth setting, feeling appreciated, and feminism are found to be key drivers.

Mumbai: Entertaining/Tradition Bound - Being funny, having an amusing / humorous, lively and entertaining with celebrity studded storyline, depicting beautiful and attractive scenery are key reasons mentioned. In addition, settings with a touch of warmth, happiness, refreshing atmosphere, and adherence to tradition are liked.

\section{Discussion}

To have a better understanding of the cultural context for these responses, a brief discussion of each city is required. The context of each city was derived from the authors' discussion with the director of a research firm. 
Hong Kong: As mentioned earlier, even though Hong Kong is part of China, it has a distinct status and warrants a city state treatment. Since the hand over to China occurred in 1997 and the SARS scare, Hong Kong has been a city that lives with a great deal of pressure and stress. Life is fast paced and much of the news is negative. Downtime is spent trying to relax, not wanting to think too much, avoiding stress, and dreaming, particularly of making money. There is an absence of religion, but spirituality is often sought only when they have troubles or fearful of evil. Therefore, a sense of Fun/Escapism is understandable for the people of Hong Kong, particularly with celebrities, entertainment, creative storylines, lovely characters, and happy and comfortable settings.

Shanghai: Is a large, crowded, international/cosmopolitan city. The pace is rushed and people feel overworked, and not properly compensated for what they do. Life is seen as dull / repetitive, just moving between home and work, and some people are cold/indifferent to others, instead wanting more time for themselves to pursue hobbies or spend time with friends and family. They treat the environment badly resulting in poor air quality, yet they are proud of the former glory and prosperity of their city. A sense of Warmth/Team Spirit is liked by Shanghainese as family is important to them as well as co-operativeness, togetherness, and pride in living in such a big and important city.

Jakarta: Is a large city and the capital of Indonesia, which is currently going through a multidimensional crisis: economic, religious and moral crisis. People are freer than 5 years ago, however, even though they are friendly people, there has been an increase in ethnic and family violence. There is a fear that eastern culture is fading, and there is a growth in extremes in the 
society with the rich getting richer, and the poor getting poorer. Traditionally they value cooperating and working together. Religious (Islamic) values are their guide. Advertisements that are Charming/Aspiring would be attractive those in Jakarta for coping with the stress of the crises in society.

Bangkok: Thailand's capital is a busy, congested city. There is uncertainty in the economy with a feeling that you cannot rely on others, and each for themselves, with the pursuit of a better quality of life. The people are good natured, placid, kind hearted, although more nervous and frightened than the country people. Family is very important, as are national pride and religion (Buddhism). A theme showing a Slice of Life is liked in Thailand, especially communicating a setting they know and relate to.

Mumbai: Formerly called Bombay, this Indian city has a large population of poor and is currently suffering rising costs, resulting in increasing tensions and financial pressures. There is less socialisation than in past, and the day to day routine is very boring / structured. Religion and celebrating festivals are important to punctuate life. However, there are strong family values and moral support. Marriage is incredibly important with $96 \%$ being arranged, and the love of family is continuous until death, as elders are consulted about everything, provide advice and guidance. There is also a belief to respect everybody, and by making others happy, helping others, and thinking of others, you are happy via their appreciation. Again, it would be logical that advertisements that are Entertaining/Tradition Bound be liked in Mumbai, to lift them from their daily routine but with adherence to tradition. 
In the focus groups, the Indians and Thais had the greatest difficulty recognising, acknowledging or expressing fears. It is felt that in both instances it is their culture that stops them from having them, or makes it hard for them to realise them (no need to). In Mumbai, everyone is complicit in the cultural framework. The framework does not let them down. They are comfortable with it and it self-fulfills - if you make others happy, it will come back to you and you will be happy. While in Bangkok, the fact that you don't know how things will work out, that you can rarely control or change it, and that it is stressful to even think about it, means that you think of religion and karma instead, and accept it. Believing that there will be a better life removes the stress.

The extent of influence culture plays in making advertising liked, depends almost entirely on the strength, uniqueness, and the values of that culture. However, it is clear to see that whatever stage the market is at, in terms of development, and the extent to which there has been influence on/dilution of traditional culture, many of the advertisements which are most liked, and resonate most, can be seen to have a very strong cultural component or focus, even if this is not immediately applicable to the viewer. This often represents nostalgia, patriotism, or desire for a simpler life.

Dependent on culture and the values associated with it, and influences which have been exerted into it, different styles and themes of advertising will be liked or rejected accordingly. However, perhaps more important, or influential than culture itself, is the relevance or meaning which the storyline/theme has to viewer concerned. An apparent pre-condition for whether an ad will be liked would appear to be whether the viewer can relate in some shape or form to what is 
portrayed, whether this be the storyline, the style/theme, the actors, the product category, or brand itself (priority in that order, or there about).

This is most clearly evidenced in:

* the local ads liked for international brands which have become so completely engrained in the culture to now (ostensibly) be seen as local brands - Coke, McDonald's, Nike, being the obvious examples;

* the local ads which have little or no direct bearing on modern city dwellers lives - Nippon paint, Fevicol, Indomie; and

* the international ads which are liked - Audi (generally, despite setting and characters not being at all local), Ikea in Jakarta (could reflect reality), Stella Artois in Bangkok (beer more relevant), John West in Hong Kong and Mumbai (unexpected, humorous).

Finally, from the focus groups it would be no surprise that the greatest optimism was observed in respondents from Mumbai, and greatest uncertainty among those in Hong Kong. Again, this can be understood from a cultural context. India is a Hindu nation where they strongly believe in karma - the good they do in this lifetime will benefit them in their next lifetime. They also believe in reincarnation, life after death, and think of life as a cycle. Making others happy, helping others, and thinking of others will make you happy via their appreciation. Therefore, it is understandable for them to be optimistic. As for Hong Kong, after the financial crisis in1997, the once happy and prosperous stock market and property speculators were then either on the verge of bankruptcy or having their job on the firing line. The worries over job, income, the downturn in economy, and SARS, have all added more stress to the Hong Kong residents. These worries might explain the higher degree of uncertainty.

\section{Conclusion}


This study sets out to investigate what contributes to ad likeability in Asia by conducting focus group interviews in Hong Kong, Shanghai, Jakarta, Bangkok and Mumbai. The focus groups interviews have resulted in a rich description of each city's likeable television commercial attributes. For Hong Kong, it is about 'Fun and Escapism'. This is no surprise given 'Asia's world city' is the bastion of competition and risk taking. Naturally life is full of pressures and entertaining, humorous and funny commercials are a way to 'switch-off' after a hard day's work. In Shanghai, it is about 'Warmth and Team Spirit', following the Confucius value where the family is the prototype of all social organisations, while the respondents of Jakarta prefer 'Aspiring and Ambitious' commercials, where idling is not encouraged in Islam. The respondents of Bangkok prefer the 'Slice of Life' commercials that they can relate to everyday. For the conservative Indians in Mumbai, 'Entertaining and Culture Bound' television commercials are preferred.

Although there are differences in the likeable attributes between the five cities, these variations can be attributed to the differences in local culture, and to a lesser degree, other market-related factors like attitudes towards advertising in general, cultural outlook and perspective, consumer confidence and hours of watching television per week. On the whole, culture appears to play a significant bearing on ad likeability in the five Asian cities, and this can still be seen through a qualitative focus group interview.

For international marketers or advertisers, knowing the local culture is of paramount importance if they want to succeed. In the case of Hong Kong, putting forward a television commercial that give the respondents a ‘big laugh’ after a hard day’s work is more appealing than a commercial 
that bombard them with facts and figures or a reminder of what the respondents had seen yesterday. Similarly the Indian respondents would expect a commercial that is entertaining albeit in a somewhat traditional form. Fam (2006) claims that culture is the root of all consumptions and so unless the international marketers or advertisers incorporate the local culture into their commercials, such as traditions and customs, values and religions, there won't be any cultural fit and hence rendering any commercials ineffective.

This study was conducted based on two sets of focus groups interviews. The interactions between group members have yielded in-depth ideas of what constitute a 'likeable' commercial. The information gathered from the interviews has allowed us to clearly define the meaning of 'likeable' for each city. Had a quantitative approach been used, the results might not have allowed for a clear cut definition. Nevertheless, it has been argued by a number of authors that group interaction can also be a major disadvantage for focus groups interview as it may inhibit the exchange of opinions and ideas from the minority or opposing points of view. In the present study, a lot of effort was undertaken to ensure that everyone in the group spoke out, but as in all group discussions, there is no way to find out what was spoken truly reflect the respondent's inner feelings. This opinion holds especially in collectivist societies like Asia where true feelings might come from one-to-one meeting rather than via a group. Hence, future research should consider a personal interview as opposed to group, but then the cost of holding such an interview might be prohibitive. Alternatively, future research should consider the nominal grouping approach where the respondents were firstly briefed by the moderator about the research problem followed by some level of group interaction. Next the respondents wrote down their ideas and opinions on a piece of paper before discussing with other group members. This method might 
bode well for research relating to ad likeability or dislikeability in collectivist societies where one’s opinion might not get suppressed by the dominating group members.

\section{References}

Aaker, D.A. and Stayman, D.M. (1990), "Measuring audience perceptions of commercials and relating them to Ad impact”, Journal of Advertising Research, Vol. 30 No. 4, pp.7-17.

Asiaweek, (2001), November 23.

Bauer, R.A. (1964), "The obstinate audience: the influence process from the point of view of social communication”, American Psychologist, Vol. 19, May, pp. 319-328.

Belk, R.W. (1985), "Issue in the intention-behavior discrepancy", Research in Consumer Behavior, Vol. 1, pp.1-34.

Belk, R.W. and Pollay, R.W. (1985), "Materialism and status appeals in Japanese and U.S. print advertising”, International Marketing Review, Vol. 2, No. 4, pp.38-47.

Belk, R.W. and Bryce, W.J. (1986), "Materialism and individual determinism in U.S. and Japanese television advertising”, Advances in Consumer Research, pp.568-572.

Biel, A, and Bridgwater, C. (1990), "Attributes of likable television commercials", Journal of Advertising Research, Vol. 30, No. 4, pp. 38-44.

Chan, K. (1999), “Cultural values in Hong Kong print advertising- 1946-96”, International Journal of Advertising, Vol.18, pp. 537-554.

Cheng, H. (1994), "Reflections of cultural values: a content analysis of Chinese magazine advertisements from 1982-1992”, International Journal of Advertising, Vol.13, pp.167-183.

Collett, P. (1994), "Youth: how do they view your commercials?", In Transcript Proceedings of the $5^{\text {th }}$ ARF Youth Research Workshop. New York: Advertising Research Foundation.

Cummins, D. (1996), “Creative failures”, Ad/Media, Vol. 11, No. 7, pp.35-37.

Crabtree, B.F. and Miller, W. (1992), Doing Qualitative Research, Sage, Newbury Park, CA.

Davies, R. (2004), “Focus groups in Asia”, http://www.orientpacific.com/focusgroups.htm

Deng, S., Jivan, S. and Hassan, M-L. (1994), “Advertising in Malaysia: a cultural perspective”, International Journal of Advertising, Vol. 13, No. 2, pp.153-166. 
Fam, K.S. (2006), “Attributes of Likeable Television Commercials in Asia”, Journal of Advertising Research, forthcoming.

Fam, K.S. and Merrilees, B. (1996), “A promotion mix budgeting model for retailing”, International Review of Retail, Distribution and Consumer Research, Vol.6, No. 4, pp. 25-37.

Fam, K.S. and Merrilees, B. (1997), "Strategic promotion planning in Australia and Hong Kong”, Journal of International Marketing and Exporting Vol. 2, No.1, pp. 4-15

Franzen, G. (1994), “Advertising Effectiveness: Findings from Empirical Research”. NTC Publications Limited.

Frith, K.T. (1996), Advertising in Asia: Communication, Culture, and Consumption, Iowa State University Press, Ames, IA.

Frith, K.T. and Sengupta, S. (1991), "Individualism and Advertising: A Cross-Cultural Comparison”, Media Asia, Vol. 18, pp.191-197.

Frith, K.T. and Wesson, D. (1991), "A comparison of culture values in British and American print advertising: a study of magazines”, Journalism Quarterly, Vol. 68, Nos. (1/2), pp. 216-23.

Greene, W. J. (1992), “Observations: what drives commercial liking?” Journal of Advertising Research, March/April: 65-68

Harley, R.I. and Baldinger, A.L. (1991), "The ARF copy research validity project”, Journal of Advertising Research, Vol. 31, No. 2, pp.11-32.

Hedges, A. (1985), “Group interviewing”, in Walker, A. (Ed.), Applied Qualitative Research, Gower, Brookfield, VT, pp. 71-91.

Hirschman, E. and Thompson, C.J. (1997), "Why media matter: toward a richer understanding of consumers relationships with advertising and mass media", Journal of Advertising, Vol. 26, No. 1, pp 43-60.

Hofstede, G. (1980), Culture's Consequences: International Differences in Work-Related Values, Beverly Hills, CA: Sage Publications.

Hollis, S. (1995), "Like it of not, liking is not enough", Journal of Advertising Research, Vol. 35, No. 4, pp. 7-16.

Katz, H. and Lee, W.N. (1992), "Ocean apart: an initial exploration of social communication differences in U.S. and U.K. prime time television advertising”, International Journal of Advertising, Vol. 11, No. 1, pp.69-82.

Keown, C. (1983), "Focus group research: tool for the retailer”, Journal of Small Business Management, Vol. 21, pp. 59-65. 
Lin, C.A. (1993), "Cultural differences in message strategies: a comparison between American and Japanese TV commercials”, Journal of Advertising Research, Vol. 33, No. 3, pp.40-48.

Lin, C.A. and Salwen, M.A. (1995), "Product information strategies of American and Japanese television advertisements”, International Journal of Advertising, Vol. 14, No. 1, pp.55-64.

MacKenzie, S.B. and Lutz, R.J. (1989), “An empirical examination of the structural antecedents of attitude-toward-the-Ad in an advertising pre-testing context”, Journal of Marketing, Vol. 53, pp.48-56.

Morgan, D. (1997), Focus Groups as Qualitative Research SAGE, Thousand Oaks.

Mueller, B. (1987), "Reflection of culture: an analysis of Japanese and American advertising appeals”, Journal of Advertising Research, Vol. 27, No. 3, pp.51-59.

Mueller, B. (1992), "Standardization vs. specification: an examination of Westernisation in Japanese advertising”, Journal of Advertising Research, Vol. 32, No. 1, pp.15-24.

O’Donohoe, S. (1994), “Advertising uses and gratifications”, European Journal of Marketing, Vol. 28, Nos. 8/9, pp. 52-75.

Pollay, R.W. and Gallagher, K. (1990), “Advertising and cultural values: reflections in the distorted mirror”, International Journal of Advertising, Vol. 9, No. 4, pp.359-72.

Postman, N. (1986), Amusing ourselves to death: public discourse in the age of show businesses, Penguin, New York.

Reed, J. and Payton, V. R. (1997), "Focus groups: issues of analysis and interpretation”, Journal of Advanced Nursing, Vol. 26, pp. 765-771.

Reeves, B. and Nass, C. (1996), The Media Equation: how people treat computers, television, and new media like real people and places, Cambridge University Press, Cambridge, UK.

Roth, M.S. (1992), “Depth versus breadth strategies for global brand management”, Journal of Advertising, Vol. 23, No. 1, pp. 97-110.

Srikandath, S.S. (1991), "Cultural values depicted in India television advertising”, The International Journal for Mass Communication Studies, Vol. 48, pp.165-175.

Stewart, D.W. and Shamdasani, P.M. (1990), Focus Groups: Theory and Practice, Sage Publications: Newbury Park CA.

Stewart, D.W. and Ward, S. (1994), "Media effects in advertising”, in Media effects: advances in theory and research, Jennings Bryant and Dolf Zillman, Eds. Erlbaum Hillsdale, NJ. 
Thorson, E. (1991), “Likeability: 10 years of academic research”, In Transcript Proceedings: Eight Annual Advertising Research Foundation Copy Research Workshop. New York: Advertising Research Foundation.

Tse, D.K., Belk, R.W. and Zhou, N. (1989), "Becoming a consumer society: a longitudinal and cross-cultural content analysis of print Ads from Hong Kong, the People's Republic of China and Taiwan”, Journal of Consumer Research, Vol. 15, No. 1, pp.457-72.

Walker, D. (1990), "Beyond validation: advertising research for the 1990s", In transcript proceedings: seventh annual advertising research foundation copy research workshop. New York: Advertising Research Foundation.

Walker, D. and Dubitsky, T.M. (1994), "Why liking matters”, Journal of Advertising Research, Vol. 3, No. 3, pp. 9-18.

Waller, D. and Fam, K. S. (2000), "Cultural values and advertising in Malaysia”, Asia Pacific Journal of Marketing and Logistics, Vol. 12, No. 1, pp.3 - 16.

Wright, L. T. (1996), "Exploring the in-depth interview as a qualitative research technique with American and Japanese firms”, Marketing Intelligence \& Planning, Vol. 14, Issue 6, pp. 59-65.

World Advertising Trends, (2001), Media Magazine, Hong Kong, Commercial Press, vol. 23, April: 1-29. 